\title{
Synthesis and Evaluation of the Lifespan-Extension Properties of Oleracones D-F, Antioxidative Flavonoids from Portulaca oleracea L.
}

\author{
Jeong A Yoon ${ }^{1,+}$, Changjin Lim ${ }^{2, \dagger}$, Dong Seok Cha ${ }^{3, *}$ and Young Taek Han ${ }^{1, *}$ \\ 1 College of Pharmacy, Dankook University, Chenan 31116, Korea; yja9477@naver.com \\ 2 College of Pharmacy, CHA University, Pocheon 11160, Korea; koryoi@cha.ac.kr \\ 3 College of Pharmacy, Woosuk University, Jeonbuk 55338, Korea \\ * Correspondence: cha@woosuk.ac.kr (D.S.C.); hanyt@dankook.ac.kr (Y.T.H.); \\ Tel.: +82-63-390-1578 (D.S.C.); +82-41-550-1431 (Y.T.H.) \\ + These authors contributed equally to this paper.
}

Received: 10 September 2019; Accepted: 24 September 2019; Published: 25 September 2019

check for updates

\begin{abstract}
Plant-derived antioxidants have been widely used as supplementary health foods, as well as having been regarded as drug candidates for aging and aging-associated diseases. Oleracones, a novel series of flavonoids isolated from Portulaca oleracea L., possess potent antioxidative activities and are expected to exhibit therapeutic potential on the aging process. The current paper describes the concise sequential synthesis of oleracones D-F. Oleracones D and F were efficiently synthesized via selective intramolecular oxa-Michael addition from oleracone E. In addition, we investigated their possible lifespan-extension properties using Caenorhabditis elegans, which is excellently suited as an experimental model to study aging. A significant longevity effect was observed when nematodes were grown with $20 \mu \mathrm{M}$ of oleracone $\mathrm{E}$.
\end{abstract}

Keywords: oleracone; flavonoid; anti-aging; longevity; Portulaca oleracea L.; Caenorhabditis elegans; total synthesis

\section{Introduction}

Aging is a complicated biological process that is controlled by a large number of genetic and environmental factors [1-4]. Many theories have been proposed to account for the aging process, but none of them offers a fully acceptable explanation. Among all the theories, the free radical theory of aging, proposed by professor Harman in 1956 [5], has been extensively investigated. This theory continues to be revised and remains a strong theory for the aging process until now. Free radical theory explains that aging is caused by cumulative oxidative stress from free radicals, resulting in cell death and, eventually, death of the organism [6]. Hence, this theory suggests that antioxidants that can sacrificially scavenge ROS (reactive oxygen species) and/or RNS (reactive nitrogen species) are effective for delaying the aging process. Indeed, early studies have indicated that plant-derived polyphenol antioxidants, including curcumin, quercetin, and resveratrol, show therapeutic potential for aging and aging-associated diseases $[7,8]$. In addition, other synthetic flavonoids have been continuously reported as novel antioxidants exhibiting antiaging properties [9-12].

Portulaca oleracea L. is a well-known annual weed, one that is widely distributed in temperate and tropical regions. This plant has been used for a long time, not only as an edible potherb, but also as a traditional medicine in many countries, being used to alleviate a wide range of illnesses [13]. In addition to phytochemical research, many pharmacological studies have been performed using the extracts or single compounds from Portulaca oleracea L. to reveal their therapeutic properties. 
Interestingly, the extracts of this plant are known to possess not only a strong in vivo antioxidant capacity, but also anti-aging activity in a D-galactose-induced mice model [14,15].

Recently, oleracones, a novel series of flavonoids, were isolated from Portulaca oleracea L. by Chinese researchers $[16,17]$. They reported the potent antioxidative potential of oleracones, which allowed us to speculate that oleracones may also possess anti-aging properties [16,17]. The current paper includes the concise sequential synthesis of oleracones and an evaluation of their possible lifespan-extension properties using Caenorhabditis elegans, an excellent experimental model to study aging. Among the reported oleracones, we planned to synthesize two homoisoflavones, oleracones $\mathrm{D}(\mathbf{1})$ and $\mathrm{F}$ (2), and a dihydrochalcone, olereacone $\mathrm{E}$ (3), which exhibit potent antioxidative effects (Figure 1).

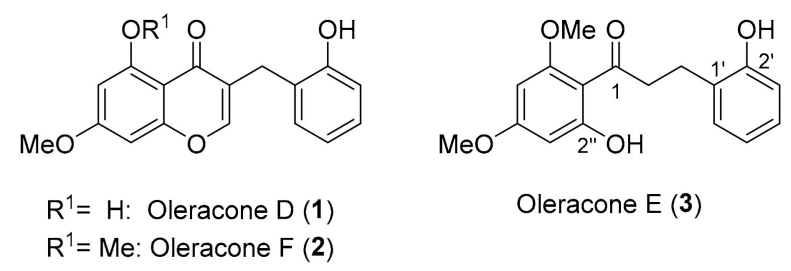

Figure 1. The structures of oleracones D (1), F (2), and E (3).

\section{Materials and Methods}

\subsection{Chemistry}

\subsubsection{General Information}

Unless noted otherwise, all reactions were performed in dry solvents under anhydrous conditions and argon atmosphere. The reaction flasks were flame-dried before use, and all solvents for extraction and chromatography were reagent grade. All reagents were purchased from commercial suppliers and were used without further purification. TLC (thin-layer chromatography) was conducted for monitoring reaction progress with $0.25 \mathrm{~mm}$ silica gel plates (Merck, Kenilworth, NJ, USA). Silica gel 60 (230-400 mesh, Merck, Kenilworth, NJ, USA) was used for flash column chromatography with the indicated solvents. ${ }^{1} \mathrm{H}$ and ${ }^{13} \mathrm{C}$ spectra were recorded on a Brucker Analytik ADVANCE digital 500 $(500 \mathrm{MHz})$ (Billerica, MA, USA) or BRUKER AVANCE-800 (800 MHz) (Billerica, MA, USA). ${ }^{1} \mathrm{H}-\mathrm{NMR}$ data are reported as follows: chemical shift, multiplicity (singlet, s; doublet, d; triplet, $t$; quartet, $\mathrm{q}$; broad b; and/or multiple resonances), coupling constant in hertz (Hz), and number of protons. Chemical shifts are stated in ppm (parts per million, $\delta$ ) downfield from tetramethylsilane (TMS) and are referenced to the deuterated solvent $\left(\mathrm{CDCl}_{3}\right.$ and $\left.\mathrm{DMSO}-\mathrm{d}_{6}\right)$. IR (infrared) spectra were recorded on a FT-IR-4200 (JASCO, Tokyo, Japan) spectrometer. Low- and high-resolution mass spectra were acquired with JMS-700 (JEOL, Tokyo, Japan) equipment.

\subsubsection{Experimental Section}

(E)-3-(2-(Benzyloxy)phenyl)-1-(2-hydroxy-4,6-dimethoxyphenyl)prop-2-en-1-one (6). To a solution of 4,6-dimethoxy-2-hydroxybenzophenone $4(700 \mathrm{mg}, 3.57 \mathrm{mmol}$ ) and 2-(benzyloxy)benzaldehyde $5(1100 \mathrm{mg}, 5.35 \mathrm{mmol})$ in ethyl alcohol $(11 \mathrm{~mL}), \mathrm{KOH}(400 \mathrm{mg}, 7.14 \mathrm{mmol})$ was added at room temperature. After stirring at the same temperature for $48 \mathrm{~h}$, the reaction mixture was concentrated in vacuo. The reaction mixture was quenched with $1 \mathrm{~N}$ aqueous solution of hydrochloric acid and extracted with EtOAc (ethyl acetate). The combined organic layer was washed with saturated sodium bicarbonate solution, dried over anhydrous magnesium sulfate, and concentrated in vacuo. Purification of the concentrated residue by flash column chromatography (EtOAc/n-Hexane $=1: 40$ to $1: 10$ ) afforded $1500 \mathrm{mg}(75 \%)$ of chalcone 6 as a yellow powder. m.p.: $114-115{ }^{\circ} \mathrm{C} ; \mathrm{R}_{\mathrm{f}}=0.25$ (EtOAc : $n$-Hexane $=1: 10) ;{ }^{1} \mathrm{H}$ NMR $\left(800 \mathrm{MHz}, \mathrm{CDCl}_{3}\right) \delta 14.37(\mathrm{~s}, 1 \mathrm{H}), 8.17(\mathrm{~d}, 1 \mathrm{H}, J=15.8 \mathrm{~Hz}), 8.02(\mathrm{~d}, 1 \mathrm{H}$, $J=15.7 \mathrm{~Hz}), 7.62(\mathrm{dd}, 1 \mathrm{H}, J=1.5,7.7 \mathrm{~Hz}), 7.46(\mathrm{~d}, 2 \mathrm{H}, J=7.6 \mathrm{~Hz}), 7.39-7.37(\mathrm{~m}, 2 \mathrm{H}), 7.33-7.30(\mathrm{~m}, 2 \mathrm{H})$, 
$7.00(\mathrm{t}, 1 \mathrm{H}, J=7.5 \mathrm{~Hz}), 6.87(\mathrm{~d}, 1 \mathrm{H}, J=8.2 \mathrm{~Hz}), 6.10(\mathrm{~d}, 1 \mathrm{H}, J=2.3 \mathrm{~Hz}), 5.91(\mathrm{~d}, 1 \mathrm{H}, J=2.3 \mathrm{~Hz}), 5.20(\mathrm{~s}$, 2H), $3.83(\mathrm{~s}, 3 \mathrm{H}), 3.72(\mathrm{~s}, 3 \mathrm{H}) ;{ }^{13} \mathrm{C}$ NMR $\left(200 \mathrm{MHz} \mathrm{CDCl}_{3}\right) \delta$ 193.3, 168.4, 166.2, 162.6, 157.9, 138.1, 136.9, $131.4,129.5,128.8,128.5,128.1,127.3,125.1,121.2,112.9,106.6,93.8,93.8,91.3,70.5,55.7,55.7$; IR (thin film, neat) $v_{\max }$ 1620, 1595, 1553, 1452, 1344, 1213, 1107, 984, 816, $760 \mathrm{~cm}^{-1}$; LR-MS (Low-Resolution Mass Spectroscopy) (FAB+) $m / z 391\left(\mathrm{M}+\mathrm{H}^{+}\right)$; HR-MS (High-Resolution Mass Spectroscopy) (FAB + ) calculated for $\mathrm{C}_{24} \mathrm{H}_{23} \mathrm{O}_{5}\left(\mathrm{M}+\mathrm{H}^{+}\right)$391.1545; observed 391.1541.

Oleracone E. (3). To a solution of chalcone $6(500 \mathrm{mg}, 1.28 \mathrm{mmol})$ in ethyl alcohol $(10 \mathrm{~mL})$, catalytic amount of $5 \%$ activated palladium on carbon was added at room temperature. After stirring for $48 \mathrm{~h}$ under $\mathrm{H}_{2}$ atmosphere, the reaction mixture was filtered through a pad of Celite and concentrated in vacuo. Purification of the concentrated residue by flash column chromatography (EtOAc: $n$-Hexane $=1$ : 10 to $1: 3)$ afforded $340 \mathrm{mg}(88 \%)$ of oleracone $\mathrm{E}(3)$ as a yellowish powder. The spectral data of 3 were consistent with previous data (Table S1). m.p.: $137-138{ }^{\circ} \mathrm{C} ; \mathrm{R}_{\mathrm{f}}=0.20($ EtOAc $/ n$-Hexane $=1: 5) ;{ }^{1} \mathrm{H}$ NMR (500 MHz, DMSO-d 6 ) $\delta 13.63$ (brs, 1H), 9.30 (brs, 1H), 7.06 (dd, 1H, J = 1.5, 7.4 Hz), 6.99 (brtd, $1 \mathrm{H}, J=1.6,7.7 \mathrm{~Hz}), 6.77(\mathrm{dd}, 1 \mathrm{H}, J=1.0,8.0 \mathrm{~Hz}), 6.70(\mathrm{td}, 1 \mathrm{H}, J=1.0,7.4 \mathrm{~Hz}), 6.11(\mathrm{~d}, 1 \mathrm{H}, J=2.4 \mathrm{~Hz})$, $6.09(\mathrm{~d}, 1 \mathrm{H}, J=2.4 \mathrm{~Hz}), 3.82(\mathrm{~s}, 3 \mathrm{H}), 3.80(\mathrm{~s}, 3 \mathrm{H}), 3.20(\mathrm{brt}, 2 \mathrm{H}, J=7.7 \mathrm{~Hz}), 2.81(\mathrm{brt}, 2 \mathrm{H}, J=7.7 \mathrm{~Hz}) ;{ }^{13} \mathrm{C}$ NMR (200 MHz, DMSO-d 6 ) $\delta 205.4,166.1,166.0,162.9,155.5,130.3,127.7,127.5,119.5,115.3,106.0,94.2$, 91.2, 56.4, 56.1, 43.9, 25.5; IR (thin film, neat) $v_{\max } 1618,1578,1489,1462,1418,1362,1204,1109$, 999, 829, $758 \mathrm{~cm}^{-1}$; LR-MS (FAB+) $\mathrm{m} / z 303\left(\mathrm{M}+\mathrm{H}^{+}\right)$; HR-MS (FAB+) calculated for $\mathrm{C}_{17} \mathrm{H}_{19} \mathrm{O}_{5}\left(\mathrm{M}+\mathrm{H}^{+}\right)$ 303.1232; observed 303.1226.

Oleracone F. (2). N,N-Dmethylformamide dimethyl acetal $(0.053 \mathrm{~mL}, 0.40 \mathrm{mmol})$ was added to a solution of oleracone $\mathrm{E}(3)(100 \mathrm{mg}, 0.33 \mathrm{mmol})$ in toluene $(5.5 \mathrm{~mL})$ at room temperature. The reaction mixture was refluxed for $2 \mathrm{~h}$, and then cooled to room temperature. The reaction mixture was concentrated in vacuo. Purification of the concentrated residue by flash column chromatography (EtOAc : $n$-Hexane $=1: 2$ ) afforded $93 \mathrm{mg}(90 \%)$ of oleracone $\mathrm{F}(2)$ as a yellow powder. The spectral data of 2 were consistent with previous data (Table S2). m.p.: $224-225^{\circ} \mathrm{C} ; \mathrm{R}_{\mathrm{f}}=0.23$ (EtOAc/n-Hexane = 1:2); ${ }^{1} \mathrm{H}$ NMR $\left(500 \mathrm{MHz}, \mathrm{DMSO}_{\mathrm{d}}\right) \delta 9.46(\mathrm{~s}, 1 \mathrm{H}), 7.88(\mathrm{~s}, 1 \mathrm{H}), 7.07(\mathrm{dd}, 1 \mathrm{H}, J=1.5,7.5 \mathrm{~Hz}), 7.01(\mathrm{brtd}, 1 \mathrm{H}$, $J=1.6,7.7 \mathrm{~Hz}), 6.78(\mathrm{dd}, 1 \mathrm{H}, J=1.0,8.0 \mathrm{~Hz}), 6.70(\mathrm{brtd}, 1 \mathrm{H}, J=1.1,7.4 \mathrm{~Hz}), 6.61(\mathrm{~d}, 1 \mathrm{H}, J=2.3 \mathrm{~Hz}), 6.48$ $(\mathrm{d}, 1 \mathrm{H}, J=2.3 \mathrm{~Hz}), 3.86(\mathrm{~s}, 3 \mathrm{H}), 3.81(\mathrm{~s}, 3 \mathrm{H}), 3.52(\mathrm{~s}, 2 \mathrm{H}) ;{ }^{13} \mathrm{C}$ NMR $\left(200 \mathrm{MHz}, \mathrm{DMSO}-\mathrm{d}_{6}\right) \delta 175.8,164.1$, $160.9,160.0,155.4,151.9,130.5,127.9,125.7,123.8,119.6,115.6,108.7,96.4,93.3,56.5,56.3,25.6$; IR (thin film, neat) $v_{\max } 1643,1595,1566,1454,1373,1207,1152,1078,824,752 \mathrm{~cm}^{-1}$; LR-MS (FAB+) $\mathrm{m} / \mathrm{z} 313$ $\left(\mathrm{M}+\mathrm{H}^{+}\right)$; HR-MS (FAB+) calculated for $\mathrm{C}_{18} \mathrm{H}_{17} \mathrm{O}_{5}\left(\mathrm{M}+\mathrm{H}^{+}\right)$313.1076; observed 313.1078.

Oleracone $D$ (1). To a solution of oleracone $\mathrm{F}(2)(150 \mathrm{mg}, 0.48 \mathrm{mmol})$ in methylene chloride $(5 \mathrm{~mL})$, $1.92 \mathrm{~mL}$ of $\mathrm{BCl}_{3}\left(1 \mathrm{M}\right.$ solution in $\left.\mathrm{CH}_{2} \mathrm{Cl}_{2}, 1.92 \mathrm{mmol}\right)$ was slowly added at $0{ }^{\circ} \mathrm{C}$. After stirring for $1 \mathrm{~h}$ at the same temperature, the reaction mixture was quenched with $\mathrm{H}_{2} \mathrm{O}$, diluted with methylene chloride, stirred for an additional $1 \mathrm{~h}$, and extracted with methylene chloride. The combined organic layer was washed with brine, dried over anhydrous magnesium sulfate, and concentrated in vacuo. Purification of the concentrated residue by flash column chromatography (EtOAc : $n$-Hexane $=1: 5$ ) afforded $114 \mathrm{mg}(80 \%)$ of oleracone $\mathrm{D}(1)$ as a yellowish powder. The spectral data of 1 were consistent with previous data (Table S3). m.p.: $154-155{ }^{\circ} \mathrm{C} ; \mathrm{R}_{\mathrm{f}}=0.31$ (EtOAc : $n$-Hexane $\left.=1: 5\right) ;{ }^{1} \mathrm{H} \mathrm{NMR}$ $(500 \mathrm{MHz}$, DMSO-d 6 ) $\delta 12.76(\mathrm{~s}, 1 \mathrm{H}), 9.47(\mathrm{brs}, 1 \mathrm{H}), 8.06(\mathrm{~s}, 1 \mathrm{H}), 7.08(\mathrm{dd}, 1 \mathrm{H}, J=1.4,7.5 \mathrm{~Hz}), 7.03$ (brtd, $1 \mathrm{H}, J=1.6,7.7 \mathrm{~Hz}), 6.81(\mathrm{dd}, 1 \mathrm{H}, J=0.8,8.0 \mathrm{~Hz}), 6.71(\mathrm{brtd}, 1 \mathrm{H}, J=1.4,7.4 \mathrm{~Hz}), 6.61(\mathrm{~d}, 1 \mathrm{H}, J=2.3 \mathrm{~Hz})$, $6.38(\mathrm{~d}, 1 \mathrm{H}, J=2.3 \mathrm{~Hz}), 3.84(\mathrm{~s}, 3 \mathrm{H}), 3.61(\mathrm{~s}, 2 \mathrm{H}) ;{ }^{13} \mathrm{C}$ NMR $\left(200 \mathrm{MHz}, \mathrm{DMSO}-\mathrm{d}_{6}\right) \delta 181.6,165.6,161.6$, $158.2,155.4,155.3,130.4,128.0,125.0,121.4,119.5,115.4,105.5,98.4,92.8,56.4,25.0$; IR (thin film, neat) $v_{\max } 1647,1585,1510,1435,1368,1240,1163,1051,822,754 \mathrm{~cm}^{-1}$; LR-MS (FAB+) $\mathrm{m} / z 299\left(\mathrm{M}+\mathrm{H}^{+}\right)$; HR-MS (FAB+) calculated for $\mathrm{C}_{17} \mathrm{H}_{15} \mathrm{O}_{5}\left(\mathrm{M}+\mathrm{H}^{+}\right)$299.0919; observed 299.0915. 


\subsection{Biology}

\subsubsection{C. elegans Maintenance}

In this paper, we used wild-type N2 nematodes which were acquired from the Caenorhabditis Genetic Center (CGC; University of Minnesota, Minneapolis, MN, USA). All nematodes were nurtured at $20^{\circ} \mathrm{C}$ on an NGM (Nematode Growth Medium) agar plate with Escherichia coli OP50 as previously reported [18]

\subsubsection{Lifespan Assay}

Lifespan assays were carried out under normal culture conditions. Age-synchronized nematodes were collected by embryo isolation and L1 arrest. The as-obtained L1 stage nematodes were grown on an NGM plate with or without of (1), (2), and (3). The survival rate of the test nematodes was determined using a dissecting microscope (SMZ1500, Nikon, Tokyo, Japan). Nematodes that failed to respond to prodding with the tip of a platinum wire were considered dead. Living nematodes were transferred to a fresh NGM plate every 2 days.

\subsubsection{Statistical Analysis}

The results obtained from the lifespan assay were plotted using Kaplan-Meier analysis, and the statistical significance between each group was analyzed using the log-rank test. The mean lifespan data were presented as the mean \pm standard deviation.

\section{Results and Discussion}

The retrosynthetic analysis for oleracones is outlined in Scheme 1. Homoisoflavone skeleton was anticipated to be efficiently prepared via a deoxybenzoin route, one of the most popular synthetic methods used for the preparation of isoflavonoids [19]. Therefore, homoisoflavone 2 and its $\mathrm{O}$-demethylated analog 1 were planned to be obtained from dihydrochalcone 3 . Oleracone E (3) was anticipated to be prepared via an aldol condensation between commercially available 4,6-dimethoxy-2-hydroxybenzophenone 4 and 2-(benzyloxy)benzaldehyde 5.

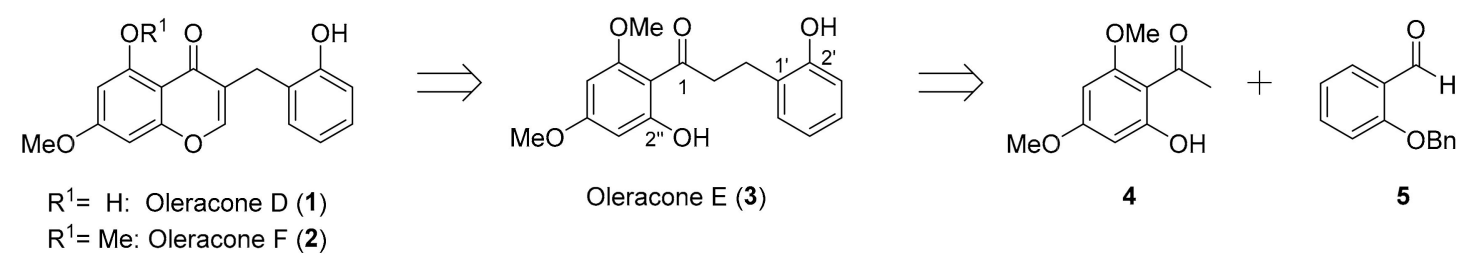

Scheme 1. Retrosynthetic analysis of oleracones D (1), F (2), and E (3).

Our synthesis was commenced with an aldol condensation between commercially available 4,6-dimethoxy-2-hydroxybenzophenone 4 and 2-(benzyloxy)benzaldehyde 5 to give chalcone 6 (Scheme 2). Concurrent hydrogenation and hydrogenolysis of the O-benzyl group in chalcone 6 using $5 \%$ activated $\mathrm{Pd}$ on carbon under $\mathrm{H}_{2}$ atmosphere led to olereacone $\mathrm{E}$ (3) in $88 \%$ yield.

We envisaged the construction of the homoisoflavone skeleton of $\mathbf{1}$ and $\mathbf{2}$ via a selective intramolecular oxa-Michael addition reaction of an enone moiety by the phenol group at the 2"-position rather than the 2'-position of intermediate 6, resulting from condensation reaction between 3 and a formyl reagent. According to our expectation, oleracone F (2) was obtained in high yield (90\%) upon stirring with $\mathrm{N}, \mathrm{N}$-dimethylformamide dimethyl acetal [20] in toluene under reflux condition, and no regioisomeric by-products were observed. The high regioselectivity observed in the reaction was attributed to the enhanced nucleophilicity of the phenol group at the 2"-position compared to that at the 2'-position in 3, which can be supported by the electron-withdrawing effect of the carbonyl group. Finally, selective $O$-demethylation of 2 using $\mathrm{BCl}_{3}$ afforded oleracone $\mathrm{D}(\mathbf{1})$ in high yield $(80 \%)$. 
The spectral data obtained for oleracones D-F (1-3) were consistent with those previously reported data $[16,17]$.<smiles>COc1cc(OC)c(C(C)=O)c(OC)c1</smiles>

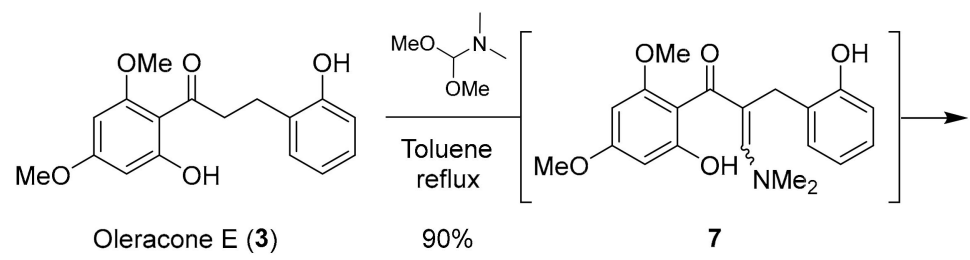<smiles></smiles>

Scheme 2. Synthesis of oleracones D (1), F (2), and E (3).

With the oleracones D-F (1-3) in hand, we examined their effects on the longevity of nematodes. To test whether oleracones exhibit lifespan-extension activity, we performed a lifespan assay using wild-type $\mathrm{N} 2$ nematodes at $20^{\circ} \mathrm{C}$, as described previously [21]. As shown in Figure 2A,B, all of the oleracones tested could prolong the lifespan of the nematodes under standard culture conditions, although the effectiveness of each compound was somewhat variable. At the maximum concentration studied $(20 \mu \mathrm{M})$, treatment with 3 and 2 extended the lifespan of nematodes by 13.8 and $11.8 \%$, respectively, compared with the control, while the efficacy of $\mathbf{1}(4.3 \%$ extension) was inferior to that of $\mathbf{2}$ and 3. Interestingly, the longevity effect of 1-3 on nematodes did not show any correlation with their radical scavenging activities ( $\mathrm{IC}_{50}$ values: $11.73,13.17$, and $17.78 \mu \mathrm{M}$, respectively) $[16,17]$. These results suggest the possibility that modulating aging-related factors may also cooperate with the direct radical scavenging activity that produces the anti-aging effect. However, detailed information on the underlying mechanism of the lifespan-extension properties of oleracone 1-3 remains to be defined. 
A

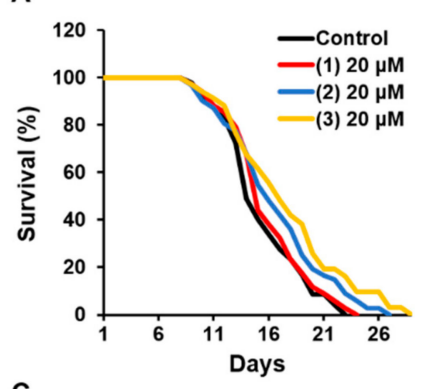

B

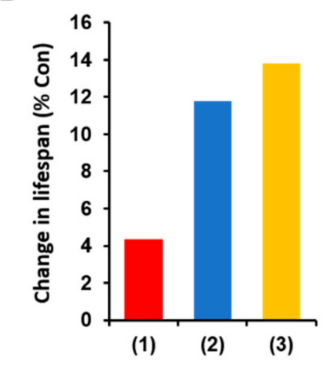

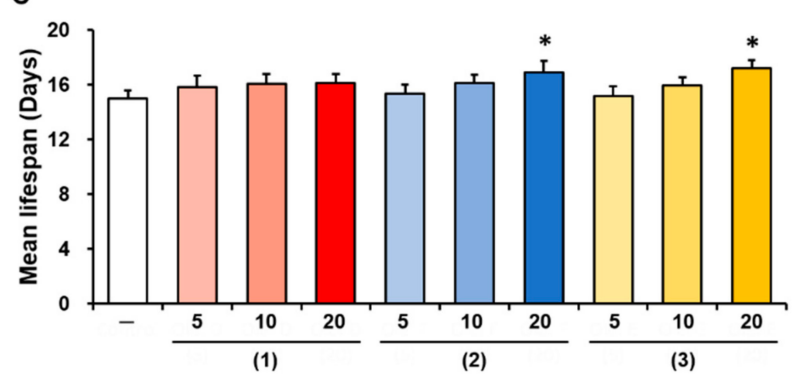

Figure 2. The longevity effect of oleracone D-F (1-3). (A) The lifespan curves obtained for compound-treated $(20 \mu \mathrm{M})$ and untreated wild-type nematodes under normal culture conditions. (B) The change in lifespan observed for the compound-treated $(20 \mu \mathrm{M})$ nematodes when compared to the control. (C) The mean lifespan of compound-treated $(5,10$, and $20 \mu \mathrm{M})$ and untreated wild-type nematodes was calculated from the survival curves. The statistical difference between the curves was analyzed using a log-rank test. ${ }^{*} p<0.05$ compared with the vehicle alone. All experiments were repeated in triplicate.

\section{Conclusions}

In summary, we concisely synthesized potent antioxidant homoisoflavones, oleracones D (1) and F (2), from dihydrochalcone olereacone E (3), and investigated their potential lifespan extension properties. Our results may shed light on the development of isoflavone-based anti-aging medications.

Supplementary Materials: The following are available online at http://www.mdpi.com/2076-3417/9/19/4014/s1, Table S1: Comparative analysis of ${ }^{1} \mathrm{H}$ NMR and ${ }^{13} \mathrm{C}$ NMR of oleracone E. Table S2: Comparative analysis of ${ }^{1} \mathrm{H}$ NMR and ${ }^{13} \mathrm{C}$ NMR of oleracone F. Table S3: Comparative analysis of ${ }^{1} \mathrm{H}$ NMR and ${ }^{13} \mathrm{C}$ NMR of oleracone D.

Author Contributions: Conceptualization, Y.T.H. and D.S.C.; formal analysis, J.A.Y.; investigation, D.S.C. and J.A.Y.; data curation, C.L.; draft preparation, C.L. and D.S.C.; review and editing, Y.T.H.; supervision, Y.T.H.; project administration, Y.T.H.

Funding: This work was supported by the National Research Foundation of Korea (NRF) grant (NRF-2017R1C1B1001826) and by the GRRC (Gyeonggi-do Regional Research Center) program of Gyeonggi province (GRRC-CHA2017-B02).

Acknowledgments: We thank Emeritus Young-Ger Suh (Seoul National University) for his helpful discussions in manuscript preparation.

Conflicts of Interest: The authors declare no conflict of interest.

\section{References}

1. Harman, D. The aging process. Proc. Natl. Acad. Sci. USA 1981, 78, 7124-7128. [CrossRef] [PubMed]

2. Harman, D. Free radical involvement in aging. Drugs Aging 1993, 3, 60-80. [CrossRef] [PubMed]

3. Harman, D. Aging: Prospects for further increases in the functional life span. AGE 1994, 17, 119-146. [CrossRef]

4. Harman, D. Aging and Disease: Extending Functional Life Span. Ann. N. Y. Acad. Sci. 1996, 786, 321-336. [CrossRef] [PubMed]

5. Harman, D. Free radical theory of againg. J. Gerontol. 1956, 12, 257-263. [CrossRef] 
6. Harman, D. The free radical theory of aging. Antioxi. Redox Signal. 2003, 5, 557-561. [CrossRef] [PubMed]

7. Conti, V.; Izzo, V.; Corbi, G.; Russomanno, G.; Manzo, V.; De Lise, F.; Di Donato, A.; Filippelli, A. Antioxidant Supplementation in the Treatment of Aging-Associated Diseases. Front. Pharmacol. 2016, 7, 24. [CrossRef]

8. Cherniack, E. The Potential Influence of Plant Polyphenols on the Aging Process. Complementary Med. Res. 2010, 17, 181-187. [CrossRef]

9. Rosa, G.P.; Seca, A.M.L.; Barreto, M.D.C.; Silva, A.M.S.; Pinto, D.C.G.A. Chalcones and Flavanones Bearing Hydroxyl and/or Methoxyl Groups: Synthesis and Biological Assessments. Appl. Sci. 2019, 9, 2846. [CrossRef]

10. Cotelle, N.; Bernier, J.; Henichart, J.; Catteau, J.; Gaydou, E.; Wallet, J. Scavenger and antioxidant properties of ten synthetic flavones. Free Radic. Biol. Med. 1992, 13, 211-219. [CrossRef]

11. Oliveira, A.M.; Cardoso, S.M.; Ribeiro, M.; Seixas, R.S.; Silva, A.M.; Rego, A.C. Protective effects of 3-alkyl luteolin derivatives are mediated by Nrf2 transcriptional activity and decreased oxidative stress in Huntington's disease mouse striatal cells. Neurochem. Int. 2015, 91, 1-12. [CrossRef] [PubMed]

12. Catarino, M.D.; Alves-Silva, J.M.; Pereira, O.R.; Cardoso, S.M. Antioxidant capacities of flavones and benefits in oxidative-stress related diseases. Curr. Top. Med. Chem. 2015, 15, 105-119. [CrossRef] [PubMed]

13. Zhou, Y.X.; Xin, H.L.; Rahman, K.; Wang, S.J.; Peng, C.; Zhang, H. Portulaca oleracea L.: A Review of Phytochemistry and Pharmacological Effects. BioMed Res. Int. 2015, 2015, 925631. [CrossRef] [PubMed]

14. Silva, R.; Carvalho, I.S. In vitro antioxidant activity, phenolic compounds and protective effect against DNA damage provided by leaves, stems and flowers of Portulaca oleracea (Purslane). Nat. Prod. Commun. 2014, 9, 45-50. [CrossRef] [PubMed]

15. Ahangarpour, A.; Lamoochi, Z.; Moghaddam, H.F.; Mansouri, S.M.T. Effects of Portulaca oleracea ethanolic extract on reproductive system of aging female mice. Int. J. Reprod. Biomed. 2016, 14, 205-212. [CrossRef]

16. Yang, X.; Zhang, W.; Ying, X.; Stien, D. New flavonoids from Portulaca oleracea L. And their activities. Fitoterapia 2018, 127, 257-262. [CrossRef] [PubMed]

17. Yang, X.; Ying, Z.; Liu, H.; Ying, X.; Yang, G. A new homoisoflavone from Portulaca oleracea L. and its antioxidant activity. Nat. Prod. Res. 2018, 32, 1-7. [CrossRef]

18. Brenner, S. The genetics of Caenorhabditis elegans. Genetics 1974, 77, 71-94.

19. Balasubramanian, S.; Nair, M.G. An Efficient "One Pot" Synthesis of Isoflavones. Synth. Commun. 2000, 30, 469-484. [CrossRef]

20. Kirkiacharian, B.S.; Gomis, M. New Convenient Synthesis of Homoisoflavanones and ( \pm )-Di-Omethyldihydroeucomin. Synth. Commun. 2005, 35, 563-569. [CrossRef]

21. Kim, Y.S.; Han, Y.T.; Jeon, H.; Cha, D.S. Antiageing properties of Damaurone D in Caenorhabditis elegans. J. Pharm. Pharmacol. 2018, 70, 1423-1429. [CrossRef] [PubMed] 